\title{
MUC2 is the prominent colonic mucin expressed in ulcerative colitis
}

\author{
K M A J Tytgat, F J M Opdam, A W C Einerhand, H A Büller, J Dekker
}

\begin{abstract}
Background-It has been shown that MUC2 is the prominent mucin synthesised in healthy colon.

Aim-To identify the predominant mucins in ulcerative colitis (UC) and to study their biosynthesis.

Methods and Results-Mucin was purified from UC resection specimens. This mucin on sodium dodecylsulphate polyacrylamide gel electrophoresis (SDSPAGE) presented as one, high molecular weight, periodic acid/Schiff's reagent (PAS) stainable band. Amino acid composition showed a close resemblance to that of MUC2. Immunoprecipitation with a specific anti-MUC2 antiserum confirmed that this mucin was MUC2. In addition, on the mRNA level MUC2 was also the most prominent mucin expressed in UC. Polyclonal antiserum was elicited, mainly recognising mucin peptide epitopes of UC and normal colonic mucin. Biosynthetic studies with $\left[{ }^{35} \mathrm{~S}\right]$ amino acids showed that the MUC2-precursor in UC displayed a molecular mass on SDSPAGE of approximately $600 \mathrm{kDa}$. This precursor was converted into a mature MUC2 with anomalous mobility on SDSPAGE of $550 \mathrm{kDa}$ and was secreted. Only this $550 \mathrm{kDa}$ band could be labelled with $\left[{ }^{35}\right.$ S] sulphate and stained by PAS. Conclusions-This study shows that in parallel with the mucin expression in healthy controls, MUC2 is the major mucin expressed in UC. Qualitatively, MUC2 biosynthesis seems unchanged in UC.

(Gut 1996; 38: 554-563)
\end{abstract}

Keywords: mucin, ulcerative colitis, MUC2, biosynthesis.

\author{
Department of \\ Paediatric \\ Gastroenterology and \\ Nutrition, Academic \\ Medical Centre, \\ Amsterdam, the \\ Netherlands \\ K M A J Tytgat \\ F J M Opdam \\ A W C Einerhand \\ H A Büller \\ J Dekker \\ Correspondence to: \\ Department of Paediatric \\ Gepartment of Paediat \\ Gastroenterology and
Nutrition, Academic Medical \\ Centre, Meibergdreef 9, \\ Rm G8-260, 1105 AZ \\ Amsterdam, the \\ Netherlands. \\ Accepted for publication \\ 23 October 1995
} sequences of amino acids that are repeated several times in the protein. ${ }^{3}$ These tandem repeats contain large numbers of serine and threonine residues, which are heavily $\mathrm{O}$-glycosylated. Terminally, negatively charged sialic acid and sulphate residues may be attached to the oligosaccharide chains, giving the mucins an overall negative charge. ${ }^{4-6}$ To date, eight human mucin genes have been identified, designated MUC1-8 and their coding sequences have been partially or completely determined. ${ }^{7-14}$ These mucin genes show tissue specific expression. Previously, we have shown that MUC2 is the most prominent secretory mucin in normal colon. ${ }^{15}$ MUC2 is synthesised as a high mannose $N$-glycosylated precursor of about $600 \mathrm{kDa}$, which is subsequently heavily $O$-glycosylated, sulphated, and secreted. The mature mucin exhibits an aberrant mobility on sodium dodecylsulphate polyacrylamide gel electrophoresis (SDS-PAGE) of approximately $550 \mathrm{kDa}$, while gel filtration showed that it was actually much larger. ${ }^{15}$

It has been suggested that changes in mucin expression or composition could lead to a changed protective barrier function of mucus (reviewed in ref 16). A number of changes in colonic mucus and mucin have been reported in association with UC. In active UC, the number of goblet cells, which synthesise the secretory mucins, are reduced and the mucus gel layer is thinner compared with mildly inflamed colon, independent of treatment. ${ }^{17} 18$ Concerning the $O$-glycosylation of mucins, a reduction in mean number of sugar residues per oligosaccharide side chain has been reported, ${ }^{19}$ most probably resulting from premature termination of $O$-glycosylation, leading to subsequent exposure of 'core-region' structures of the $O$-linked oligosaccharides. ${ }^{520}$ Histochemically, a decrease in sulphomucins, with a reciprocal rise in sialomucins has been shown. ${ }^{21-23}$ Some controversy still exists, however, regarding the staining techniques, because a comparative rise in either sialic acid or sulphate residues may change the balance of the staining pattern, independent of the exact number of these residues. ${ }^{22} 24$ Nevertheless, sialic acid residues seem to be increased, with loss of $O$-acetyl substitutions. ${ }^{24-26}$ As only $\mathrm{O}$-glycosylation was studied and not the underlying mucin gene expression, it was unclear, whether the abnormalities in $\mathrm{O}$-glycosylation result from changed post-translational processing or from changes in expression of different mucins. In fact, until recently, it was unknown which mucins were expressed in colon and whether the expression of these mucins was changed in UC.

In this study, our goal was to determine if MUC2 was also the major mucin in colon affected by UC and to compare mucin biosynthesis qualitatively. Therefore, we used the same isolation procedures as for normal human colonic mucin (HCM) to independently isolate mucin from colon affected by UC, referred to as human colitic colonic mucin 
(HCCM). Amino acid and carbohydrate compositions of HCM and HCCM were compared and a polyclonal antiserum was raised against HCCM to study the mucin biosynthesis in UC colonic biopsy specimens. Mucin biosynthesis in UC colon was then compared with biosynthesis of mucin in normal colonic tissue. Moreover, mucin expression in normal and UC colon was independently determined by northern blotting, using DNA probes representing MUC1-6.

\section{Methods}

Unless otherwise indicated, chemicals were obtained from the following manufacturers: Gibco BRL, Gaithersburg, MD, USA; Merck, Darmstadt, Germany; Sigma Chemical, St Louis, MO, USA; Bio-Rad, Richmond, CA, USA; Pharmacia, Upsala, Sweden; BDH, Poole, England; Boehringer Mannheim, Mannheim, Germany; Amersham, Buckinghamshire, UK; and Stratagene, La Jolla, CA, USA.

The use of human tissue was approved by the human research review committee of our institution. All UC patient material was scored according to the criteria of Truelove, ${ }^{27}$ based on the clinical history, the endoscopic findings as well as the histology, as suffering from mild or severe colitis or colitis in remission.

\section{Isolation of HCCM}

Isolation of mucin from UC colon HCCM, was performed in a similar manner to the isolation of mucin from normal human colon (HCM $),{ }^{15}$ as previously described. ${ }^{15} 28$ Surgical resection specimens, consisting of four descending and two transverse colons, were obtained from six patients, undergoing resection for UC. Two of these patients had severe UC. Three other patients had mild to moderate UC and one patient was later diagnosed as suffering from indeterminate colitis. All patients were taking corticosteroids and 5aminosalicylic acid preparations at the time of resection. Equal amounts of mucosal scrapings, about $5 \mathrm{~g}$ of wet weight, were obtained within 15 minutes after resection. Tissue scrapings were homogenised in buffer $\mathrm{pH} 7.5$, containing $6 \mathrm{M}$ guanidinium hydrochloride (Sigma), $50 \mathrm{mM}$ TRIS (Gibco), $5 \mathrm{mM}$ EDTA (Merck), and $1 \mathrm{mM}$ phenylmethylsulphonyl fluoride. Mucin was reduced by adding 100 $\mathrm{mM}$ dithiotreitol (Sigma) and stirring for 24 hours at $4^{\circ} \mathrm{C}$, followed by carboxymethylation with $250 \mathrm{mM}$ iodoacetamide (Sigma) for another 24 hours at $4^{\circ} \mathrm{C}$ in the dark. Purification was performed by equilibrium centrifugation on three consecutive $\mathrm{CsCl}$ (Boehringer) density gradients. Mucin containing fractions from each gradient were pooled and run on the next gradient. In the first and the second gradient, $\mathrm{CsCl}$ was added to a density of $1.40 \mathrm{~g} / \mathrm{ml}$, with a guanidinium hydrochloride concentration of $4 \mathrm{M}$. In the last gradient, $\mathrm{CsCl}$ was added to a density of $1.50 \mathrm{~g} / \mathrm{ml}$, whereas the guanidinium hydrochloride concentration was $0.2 \mathrm{M}$.
Isopycnic density gradient centrifugation was performed in a Beckman ultracentrifuge (Beckman, Mijdrecht, the Netherlands), Ti 60 rotor, at $50000 \mathrm{rpm}$ for 66 hours at $4^{\circ} \mathrm{C}$. Fractions were dialysed extensively against distilled water at $4^{\circ} \mathrm{C}$ and stored at $20^{\circ} \mathrm{C}$ for further analyses.

Preparation of tissue homogenates

Colonic homogenates were obtained by homogenisation of two biopsy specimens, obtained at endoscopy from a patient with mildly active UC and from a control patient with diverticular disease, in $500 \mu l$ homogenisation buffer, described in the metabolic labelling section, for one minute using a Polytron PT 1200 (Kinematica AG, Luzern, Switzerland), and then stored at $-20^{\circ} \mathrm{C}$.

\section{Biochemical analyses}

Isolated HCCM, HCM, ${ }^{15}$ and tissue homogenates were analysed on reducing SDSPAGE. ${ }^{29}$ Gels were stained with periodic acid/Schiff's reagent (PAS; Sigma) ${ }^{30}$ or with coomassie brilliant blue R-250 (CBB) (Merck). For proteinase digestion, HCCM, $\mathrm{HCM}$ as well as tissue homogenates were incubated with $0.1 \mathrm{mg} / \mathrm{ml}$ proteinase $\mathrm{K}$ (Merck) in $100 \mathrm{mM}$ ammonium bicarbonate $(\mathrm{BDH}), \mathrm{pH}$ 8.0 and $20 \mathrm{mM} \mathrm{CaCl}_{2}$, for one hour at $37^{\circ} \mathrm{C}$. Proteinase $\mathrm{K}$ digestion was stopped by addition of $1 \mathrm{mM}$ phenylmethylsulphonyl fluoride (Sigma). Buoyant density of HCCM was measured by weighing $1 \mathrm{ml}$ of $\mathrm{CsCl}$ density gradient fractions containing HCCM. Hexose assay was performed using orcinol (Sigma). ${ }^{31}$ Monosaccharide composition was analysed. ${ }^{32}$ Amino acid analysis was performed using $o$-phtalaldehyde (Pierce Europe, Oud-Beyerland, the Netherlands) derivative technique and high performance liquid chromatography. ${ }^{33}$

\section{Preparation and characterisation of polyclonal antiserum}

One ml containing approximately $100 \mu \mathrm{g}$ purified HCCM, was mixed with $1 \mathrm{ml}$ of Freund's complete adjuvant (Difco, Detroit, MI, USA) and injected subcutaneously in a New Zealand white rabbit. On day 14 and day 21 , booster injections were given, with $1 \mathrm{ml}$ of the antigen, mixed with $250 \mu \mathrm{l}$ of Freund's incomplete adjuvant (Difco). On day 27, $50 \mathrm{ml}$ of blood was collected and polyclonal antihuman colitic colonic mucin antiserum (anti-HCCM) was obtained. Anti-MRP, a specific anti-MUC2 antiserum, was kindly provided by Professor $\mathrm{Y}$ $S \mathrm{Kim} .{ }^{34}$ Anti-HCM was raised against HCM as described previously. ${ }^{15}$ Purified mucins and tissue homogenates, with or without proteinase $\mathrm{K}$ digestion, from normal and UC colon were run on $3 \%$ stacking $/ 4 \%$ running SDS-PAGE. Part of the gel was blotted on nitrocellulose (Nitran, Schleier \& Schuell, Dassel, Germany) in a Bio-Rad Transblot Cell system for 120 minutes at $250 \mathrm{~mA}$ in $25 \mathrm{mM}$ TRIS and $192 \mathrm{mM}$ glycine (BDH). Nitrocellulose blots 
were incubated with anti-HCM or antiHCCM, diluted 1:100 in blot buffer, containing $50 \mathrm{mM}$ TRIS, pH 7.8; 5\% (wt/vol) non-fat dry milk powder (Lyempf, Kampen, the Netherlands); $2 \mathrm{mM} \mathrm{CaCl}$ (Sigma); $0.05 \%$ Nonidet P40 (BDH); and $0.01 \%$ (vol/vol) antifoam (Sigma), followed by incubation with goat antirabbit IgG conjugated to horseradish peroxidase and staining with diaminobenzidine.

\section{Histochemical examination}

Sigmoidal biopsy specimens obtained at endoscopy from patients with UC were fixed and sections were sliced for histochemical examination. ${ }^{35}$ Adjacent sections were used for staining with haematoxylin and azofloxin ${ }^{36}$ or alcian blue, $\mathrm{pH} 2 \cdot 5 /$ nuclear fast $\mathrm{red}^{37}$ or for immunohistochemistry. ${ }^{35}$ The sections were incubated with 1:500 anti-HCCM, or 1:500 anti-HCM for immunohistochemical tests. As a control, the first antiserum was omitted.

\section{Metabolic labelling studies}

Biopsy specimens were obtained from sigmoid colon from patients with UC, from moderately inflamed, but non-ulcerated areas. Alternatively, for comparison with normal colon, sigmoid biopsy specimens were obtained from patients without a history of UC, undergoing control colonoscopy after polypectomie or diagnostic colonoscopy where no mucosal abnormalities could be detected. Specimens were labelled with $\left[{ }^{35} \mathrm{~S}\right.$ ] amino acids (In Vitro Cell Labelling Mix, specific activity 1000 $\mathrm{Ci} / \mathrm{mmol}$, Amersham), containing about $65 \%$ $\mathrm{L}-\left[{ }^{35} \mathrm{~S}\right]$ cysteine, to label the polypeptide, or with $\left[{ }^{35}\right.$ S] sulphate (specific activity 1050 $\mathrm{Ci} / \mathrm{mmol}$, Amersham), to label the mature, sulphated glycoprotein according to methods previously validated. 152838 Briefly, immediately after the biopsy, the tissue was placed in $100 \mu \mathrm{l}$ Eagle's minimal essential medium (Gibco BRL) supplemented with non-essential amino acids, penicillin and streptomycin, and glutamine (all from Sigma) at $37^{\circ} \mathrm{C}$ under $95 \%$ $\mathrm{O}_{2} / 5 \% \mathrm{CO}_{2}$. Pulse labelling is defined as a period of 45 minutes, in which $100 \mu \mathrm{Ci}$ $\left.{ }^{35} \mathrm{~S}\right]$ amino acids were added to $100 \mu \mathrm{l}$ medium containing the specimen, or $100 \mu \mathrm{Ci}$ $\left.{ }^{35} \mathrm{~S}\right]$ sulphate was added to $100 \mu \mathrm{l}$ medium minus sulphate, containing the specimen. Chase incubation is defined as a period of four hours, after either the $\left[{ }^{35} \mathrm{~S}\right]$ amino acids or the $\left[{ }^{35} \mathrm{~S}\right]$ sulphate pulse labelling, when the medium containing the radioactive label was exchanged for Eagle's minimal essential medium without label, supplemented with 0.5 $\mathrm{mM}$ methionine (Sigma) and $0.1 \mathrm{mM}$ cysteine (Sigma). Specimens were homogenised in homogenisation buffer containing $50 \mathrm{mM}$ TRIS, pH 7.5, $5 \mathrm{mM}$ EDTA, $1 \%$ (wt/vol) Triton X-100 (BDH), $100 \mu \mathrm{g} / \mathrm{ml}$ pepstatin A (Sigma), $100 \mu \mathrm{g} / \mathrm{ml}$ leupeptin (Sigma), 1 $\mathrm{mg} / \mathrm{ml}$ soybean trypsin inhibitor (Sigma), 0.24 $\mathrm{U} / \mathrm{ml}$ aprotinin (Sigma), and $1 \mathrm{mM}$ phenylmethylsulphonyl fluoride (Sigma). Mucin was immunoprecipitated from labelled homo- genates or from chase medium overnight at $4^{\circ} \mathrm{C}$, using $30 \mu \mathrm{l}$ anti-HCCM, anti-HCM or anti-MRP. The immunocomplexes were precipitated using protein A coupled to Sepharose Cl-4B. Immunoprecipitated mucin was analysed on $3 \%$ stacking $/ 4 \%$ running SDSPAGE, which was stained with PAS and subsequently fluorographed. For molecular weight markers, unreduced $\left.{ }^{35} \mathrm{~S}\right]$ amino acids labelled rat gastric mucin precursor was used, with molecular mass of $300 \mathrm{kDa}$ for the monomer and $600 \mathrm{kDa}$ for the dimer ${ }^{38}$ and prestained high molecular weight markers, with molecular masses between 49.5 to $205 \mathrm{kDa}$ (BioRad).

\section{Northern blot analysis}

MUC1 (about $450 \mathrm{bp}$ ), MUC2 (about 900 bp), and MUC3 (about $400 \mathrm{bp}$ ) sequences, cloned in the EcoRl site of pBluescript (Stratagene), have been described.893940 pUC19 containing MUC5A/C (about 1700 bp) sequence was kindly provided by $\mathrm{Dr} L$ Klomp. ${ }^{41}$ MUC4 (48 bp) sequence was obtained by a standard polymerase chain reaction procedure ${ }^{42}$ using MUC4 gene specific primers (see later) and an antisense MUC4 oligonucleotide as template. This template was kindly provided by Dr H Vos and is based on the sequence published by Porchet of 5'GTCGGTGACAGGAAGAGGGGTGGCGTGACCTGTGGATGCTGAGGAAGT $3^{\prime} .^{10}$ MUC6 DNA (about $260 \mathrm{bp}$ ) was also obtained by a polymerase chain reaction using MUC6 gene specific primers (see later) and human genomic DNA as template. After amplification MUC4 and MUC6 DNA fragments were digested with EcoRl and Sall and separated on a $2.5 \%$ agarose gel by standard procedure. ${ }^{42}$ Subsequently, the DNA fragments were isolated from the gel using Qiaex gel extraction kit (Qiagen, Chatsworth, CA, USA) as described by the manufacturer, and cloned in the corresponding sites of pBluescript. Sequences were verified by sequence analysis using Sequenase 2.0 (USB, Cleveland, $\mathrm{OH}, \mathrm{USA}$ ) as described by the manufacturer. All DNA probes used for northern blot analysis were obtained by digestion of the appropriate restriction enzymes and separation on agarose gels by standard procedure. ${ }^{42}$ The DNA probes were isolated using the Qiaex gel extraction kit, and labelled with $\alpha-{ }^{32} \mathrm{P}-\mathrm{dATP}$ by the random prime labelling procedure. ${ }^{42}$ All probes were first tested and showed positive reaction with corresponding mRNA.

There follows the oligonucleotides in which the engineered EcoRl (GSP-1) and Sall (GSP2) restriction sites are underlined.

MUC4 GSP-1: 5'GGAATTCGTCGGTGACAG 3'. MUC4 GSP-2: 5'CTCTGTCGACTTCCTCAG 3'. MUC6 GSP-1: 5' GGAATTCTGGAGTCACCAAGGTGGAGAAAGGTGG 3'. MUC6 GSP-3: 5'CTCTGTCGACACCACTCAGCACCAGCAGCAG 3'.

RNA was isolated from four sigmoidal biopsy specimens per patient, using the RNeasy total RBA kit (Qiagen), according to manufacturer's protocol. RNA samples $(5 \mu \mathrm{g})$ 
Amino acid and sugar composition of $\mathrm{HCM}^{15}$ and HCCM (mol\%)

\begin{tabular}{|c|c|c|}
\hline & $H C C M$ & $H C M$ \\
\hline \multicolumn{3}{|l|}{ Amino acid } \\
\hline Alanine & 3.9 & 1.9 \\
\hline Arginine & $1 \cdot 7$ & $>0^{\star}$ \\
\hline Asparagine & $6 \cdot 6$ & $5 \cdot 4$ \\
\hline Cysteine & ND & ND \\
\hline Glutamic & $8 \cdot 3$ & $6 \cdot 4$ \\
\hline Glycine & $13 \cdot 2$ & 11.5 \\
\hline Histidine & 1.0 & 0.7 \\
\hline Isoleucine & $3 \cdot 0$ & $1 \cdot 7$ \\
\hline Leucine & $4 \cdot 0$ & $3 \cdot 6$ \\
\hline Lysine & $2 \cdot 3$ & $1 \cdot 4$ \\
\hline Methionine & $0 \cdot 2$ & $>0^{\star}$ \\
\hline Phenylalanine & $1 \cdot 7$ & $>0^{\star}$ \\
\hline Proline & $9 \cdot 8$ & $16 \cdot 1$ \\
\hline Serine & 9.9 & $8 \cdot 0$ \\
\hline Threonine & $28 \cdot 5$ & $38 \cdot 5$ \\
\hline Tyrosine & $2 \cdot 3$ & 0.6 \\
\hline Valine & $3 \cdot 8$ & $4 \cdot 5$ \\
\hline \multicolumn{3}{|l|}{ Carbohydrate } \\
\hline Fucose & $9 \cdot 8$ & $5 \cdot 0$ \\
\hline Mannose & 1.9 & $2 \cdot 1$ \\
\hline Galactose & $21 \cdot 6$ & $16 \cdot 8$ \\
\hline GalNAc & $10 \cdot 8$ & $12 \cdot 4$ \\
\hline GICNAC & $33 \cdot 0$ & $44 \cdot 2$ \\
\hline NANA & 22.9 & 19.6 \\
\hline
\end{tabular}

ND: not determined.

Present in small amounts, but conflicting data.

were separated on $0.8 \%$ agarose gels containing $10 \mathrm{mM}$ HEPES (Sigma) $\mathrm{pH} 7.5$ and $2.2 \mathrm{M}$ formaldehyde. The gel was treated with 50 $\mathrm{mM} \mathrm{NaOH}$ for 15 minutes and neutralised in $20 \times$ SSC, consisting of $3 \mathrm{M}$ sodium chloride and $0.3 \mathrm{M}$ sodium citrate $\mathrm{pH} 7 \cdot 0$, for 20 minutes. Capillary transfer of the RNA to $\mathrm{N}$-hybond (Amersham) was carried out. ${ }^{42}$ Hybridisation and washing of the northern blot sample was performed as described. ${ }^{43}$

\section{Results}

Almost identical amounts of mucin were isolated from UC patients, compared with normal controls $^{15}$ (about $10 \mathrm{mg}$ from $5 \mathrm{~g}$ wet weight mucosal scrapings) after triple $\mathrm{CsCl}$ density gradient purification. In the first gradient, fractions with densities between 1.35 and 1.50 $\mathrm{g} / \mathrm{ml}$ showed on SDS-PAGE a high molecular weight glycoprotein that could be stained by PAS. In these fractions, however, some

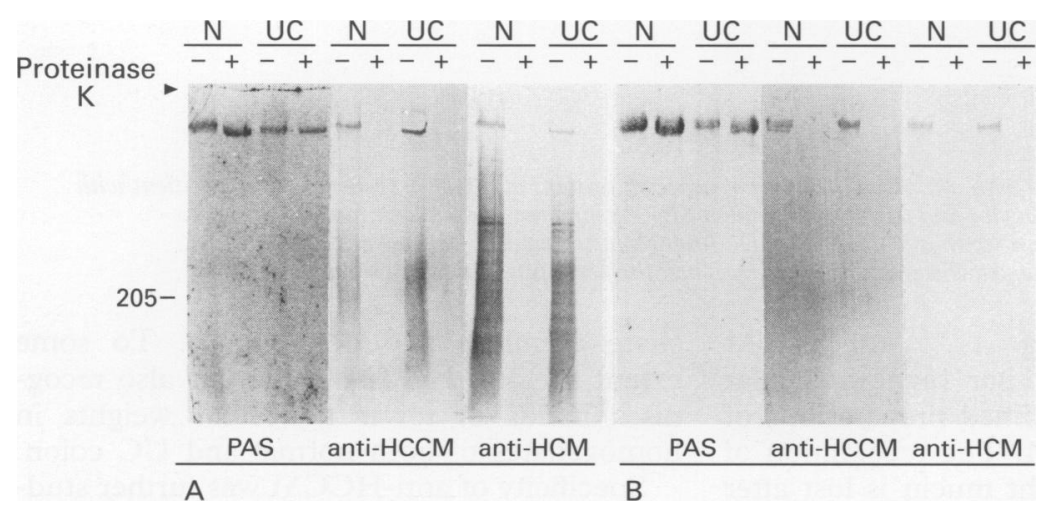

Figure 1: Normal and UC colonic homogenates and purified HCM and HCCM analysed by SDS-PAGE and western blotting. (A) Shows tissue homogenates and (B) shows purified mucins. $N$ shows either normal colonic homogenate or isolated HCM. UC shows either colonic homogenate from UC colon or isolated HCCM. Digestions with or without proteinase $K$ are shown. PAS shows staining of gel with PAS. Anti-HCCM shows western blot of the gel containing samples identical to the corresponding PAS stained gel, incubated with anti-HCCM. Anti-HCM shows western blot of the gel containing samples identical to the corresponding PAS stained gel, incubated with anti-HCM. Arrowhead points to the border between 3\% stacking and 4\% running reducing SDS-PAGE. To the left is shown the prestained high molecular mass marker of $205 \mathrm{kDa}$. additional bands of lower molecular masses could be stained by CBB, indicating the contamination with other proteins. In the second gradient, the fractions containing the high molecular weight PAS positive band were free of other proteins, and CBB only stained proteins in fractions with a density of less than 1.20 $\mathrm{g} / \mathrm{ml}$. In the third gradient, fractions with densities varying between $1 \cdot 25-1 \cdot 55 \mathrm{~g} / \mathrm{ml}$, showed on PAS staining of SDS-PAGE one high molecular weight band (results not shown). None of the fractions of the third gradient contained any material that could be stained by CBB. These fractions corresponded to a peak in the hexose content as determined by orcinol assay (results not shown). These fractions were pooled and were considered to contain purified HCCM. Mean buoyant density of HCCM was $1.29 \mathrm{~g} / \mathrm{ml}$ compared with $1.48 \mathrm{~g} / \mathrm{ml}$ for HCM. ${ }^{15}$ The Table shows carbohydrate and amino acid analyses of HCCM compared with HCM. Amino acid composition shows a distribution characteristic for mucin, with high amounts of serine, threonine, and proline residues. The amino acid composition of HCCM resembles that of $\mathrm{HCM}$ and of MUC2, as was deduced from the MUC2 cDNA. ${ }^{44} 45$ The carbohydrate composition shows the six monosaccharides that are known to be present in mucins (Table). Similar to HCM, the sialic acid content in HCCM is very high.

When colonic homogenates were analysed on reducing SDS-PAGE, and stained with PAS, one high molecular weight product could be visualised (Fig 1A). This PAS stained band is present in both normal and UC tissue homogenates. Moreover, the molecular weights of these PAS stained bands in tissue homogenates are comparable with purified HCM as well as purified HCCM stained by PAS (Fig 1, A and B). This shows that normal and UC colonic mucin are both visible by PAS staining on low percentage SDS-PAGE as one high molecular weight band, migrating to a similar position in the gel, being virtually the only product visible in PAS stained tissue homogenates.

Heavy $O$-glycosylation is known to protect the large central part of the polypeptide of mucins against proteolytic degradation. ${ }^{3}$ This proteinase $\mathrm{K}$ resistant central part of the mucin is referred to as the glycopeptide. In contrast, the $\mathrm{C}$ - and $\mathrm{N}$-terminal protruding parts of the protein are far less glycosylated, rendering these parts susceptible to proteolytic degradation. ${ }^{3}$ Proteinase $\mathrm{K}$ digestion of either HCM or HCCM resulted in only a slight shift in mobility of both PAS stained mucin bands (Fig 1). Thus, a very large part of the mucin molecules, most probably representing the glycopeptide, remained intact as visualised by the similar intensity of PAS staining, showing that only the comparatively small proteinase $\mathrm{K}$ sensitive parts of the mucin were digested. Part of the gel, containing identical samples, was used for western blotting. Anti-HCCM, raised against purified HCCM, reacted mainly with a high molecular weight band of similar mobility as the PAS stained bands, in normal as well as 

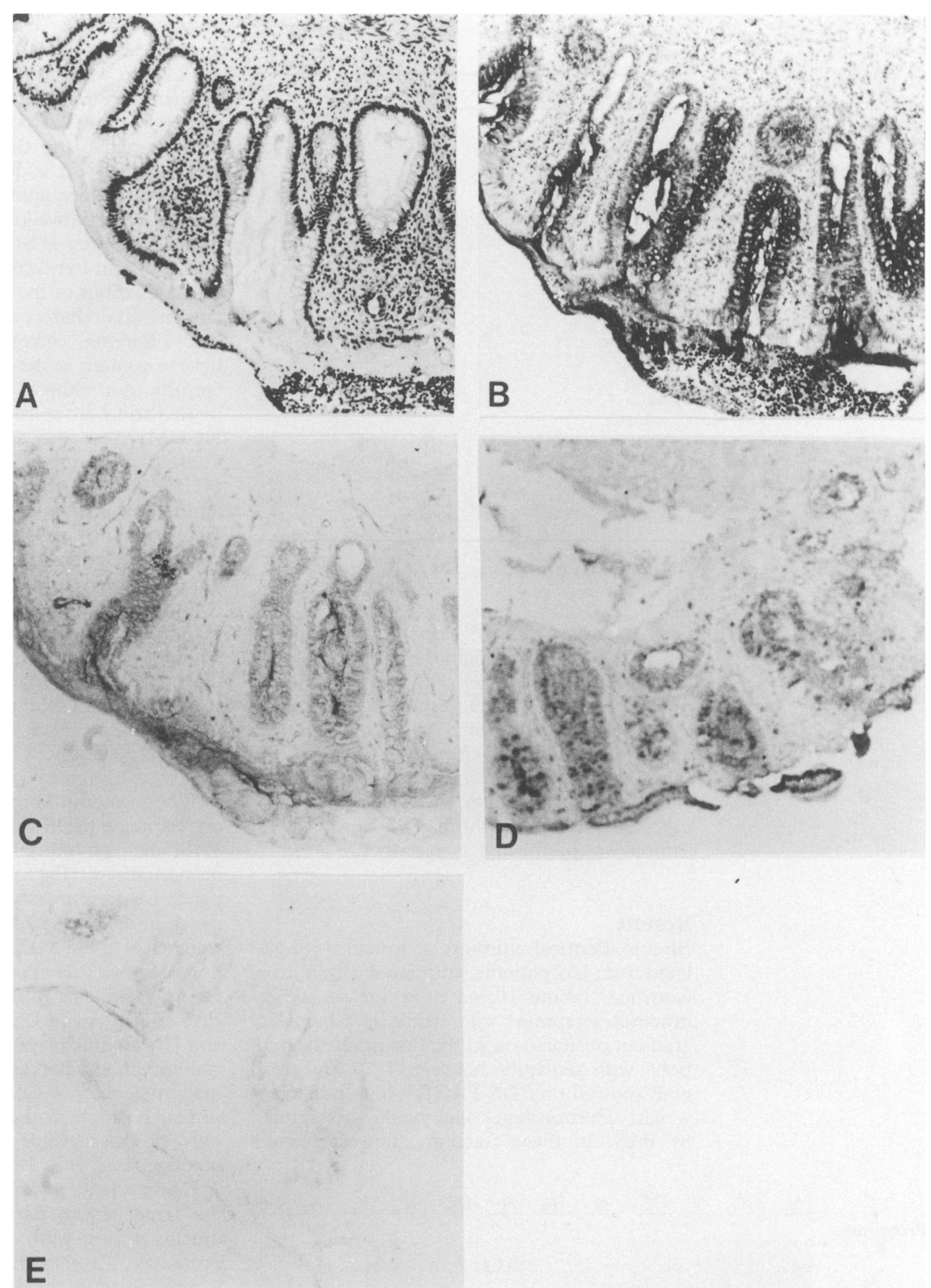

Figure 2: Immunohistochemistry with antimucin antisera of adjacent sections of a biopsy specimen from a patient with mildly active UC. (A) Haematoxylin and azofloxin staining. (B) Alcian blue and nuclear fast red staining. (C) Immunohistochemical staining with anti-HCCM. (D) Immunohistochemical staining with anti-HCM.

(E) Negative control for immunohistochemical staining, in which the first antiserum was omitted.

UC homogenates (Fig 1). Anti-HCCM reacted further with similar high molecular weight bands, in the purified preparations of HCM as well as HCCM. The recognition of the high molecular weight mucin is lost after proteinase $\mathrm{K}$ digestion, although the PAS staining shows that the proteinase $\mathrm{K}$ resistant mucin glycopeptides are still intact (Fig 1). As only the small protruding, relatively unglycosylated peptide parts were cleaved off by proteinase $\mathrm{K}$, this suggests first that anti-HCCM mainly recognises peptide epitopes on the mucins and secondly, that HCM and HCCM share common peptide epitopes. To some extent the anti-HCCM antiserum also recognises bands of lower molecular weights in homogenates of both normal and UC colon. Specificity of anti-HCCM was further studied using immunohistochemistry on tissue sections of a biopsy specimen from a patient with clinical and endoscopic mildly active UC. Haematoxylin and azofloxin staining shows a mildly active UC, with crypt distortion and neutrophilic infiltrate (Fig 2A). Alcian blue and nuclear fast red staining of an adjacent tissue section (Fig 2B), shows an almost 


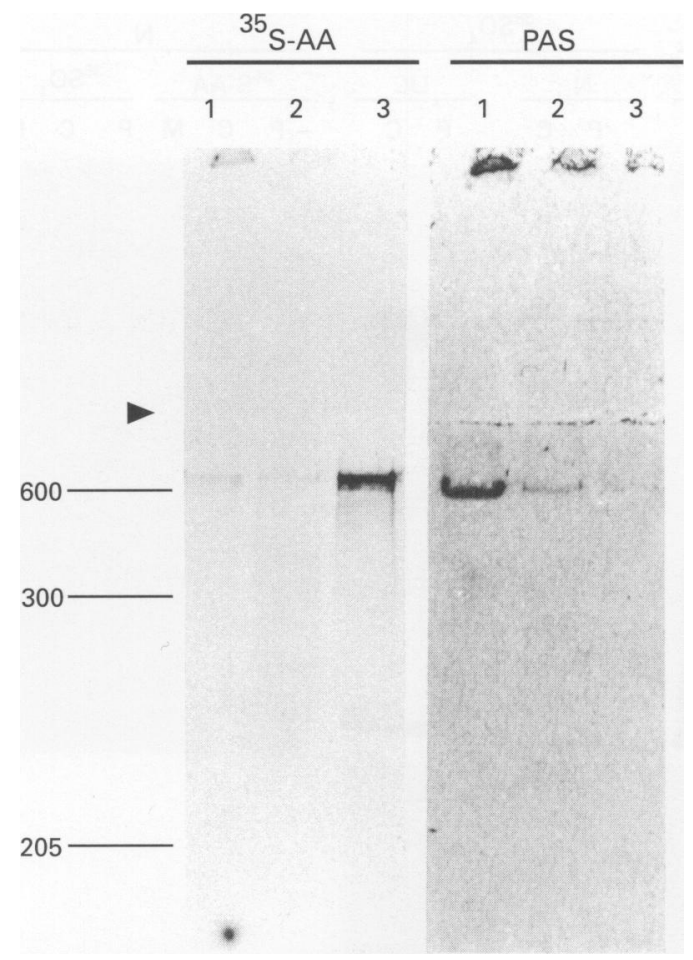

Figure 3: Identification of HCCM as MUC2. (Left): Immunoprecipitations of identical aliquots of a ${ }^{35}$ S] amino acid labelled $\left.{ }^{35} S-A A\right)$ UC colonic homogenate: lane 1; anti-HCM, lane 2; anti-HCCM, and lane 3; anti-MRP. (Right): PAS-staining (PAS) of the same gel containing the immunoprecipitations displayed in the left panel. Arrowhead shows the border between 3\% stacking and 4\% running reducing SDS-PAGE. In left margin unreduced rat gastric mucin precursor marker of $300 \mathrm{kDa}$ and $600 \mathrm{kDa}$ and the prestained high molecular mass marker of $205 \mathrm{kDa}$ are shown.

complementary picture when compared with Fig 2A, because alcian blue at $\mathrm{pH} 2.5$ specifically stains mucins in goblet cells, while these mucins remain virtually unstained in Fig $2 \mathrm{~A}$. Anti-HCCM (Fig 2C) and anti-HCM (Fig 2D) show reactivity exclusively towards all goblet cells that were also stained by alcian blue.

As the predominant mucin in normal colon was identified as MUC2, we set out to identify HCCM, using specific anti-MUC2 antisera.
A

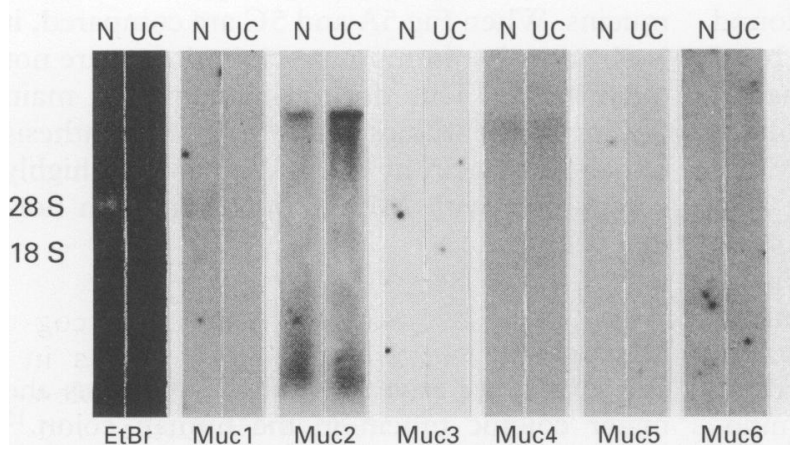

B
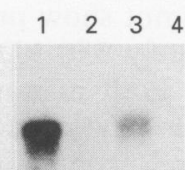

Muc3
Figure 4: Northern blot analysis of total RNA isolated from colonic biopsy specimens of a healthy control and of a UC patient, with MUC1 to MUC6 probes. (A) N shows total $R N A$ from control patient, and UC shows total RNA from a patient with mildly active UC. EtBr shows ethidium bromide fluorograph of the samples before northern blotting, showing that similar amounts of RNA were analysed. Northern blot was probed with MUC1-MUC6 DNA probes. In all panels, the same blot was used. After incubation with each probe, the blot was washed extensively until no radioactivity could be detected before incubation with the next probe. (B) Northern blot analysis of total RNA (5 $\mu g$ per lane) from human tissues: 1 , jejunum; 2, colon; 3 , gall bladder; 4, stomach, hybridised with MUC3 DNA probe. $28 S$ and $18 S$, show the ribosomal RNA bands.
Two biopsy specimens, taken from the same patient described in Fig 2, were pulse labelled with ${ }^{35}$ S ] amino acids. After homogenisation, the homogenate was divided in three equal aliquots and mucin was immunoprecipitated using anti-HCM, anti-HCCM or anti-MRP, another specific and independently obtained anti-MUC2 antiserum (Fig 3). All three antisera immunoprecipitated a similar $\left[{ }^{35} \mathrm{~S}\right]$ amino acids labelled band, with molecular mass around $600 \mathrm{kDa}$ (Fig 3). This band was identified previously in normal colon as the MUC2 precursor. ${ }^{15}$ Both anti-HCM and anti-HCCM were not only able to immunoprecipitate the HCCM precursor, but also a high molecular mass band of approximately $550 \mathrm{kDa}$, as visualised by PAS staining (Fig 3). This $550 \mathrm{kDa}$ band was identified previously as mature colonic MUC2. ${ }^{15}$

Expression of mucins in UC colon was also studied at the mRNA level. Total RNA was isolated from biopsy specimens of a patient with mild UC and from a control patient who underwent control colonoscopy. Northern blot analysis of total RNA was carried out using MUC1-MUC6 cDNA as probes (Fig 4A). These northern blots showed virtually no signal of MUC1, MUC3, MUC5AC, and MUC6 and low signal for MUC4 (Fig 4A). In contrast, MUC2 expression was high, showing hybridisation with a high molecular weight band and also hybridisation with low molecular weight mRNA degradation products (Fig 4A). Expression of MUC1-MUC6, as detected by the various probes, did not differ between the UC patient and the control (Fig 4A). All probes were shown to give positive signal with RNA preparations from tissue known to express the corresponding mRNA. MUC3 showed positive signals in human jejunum and gall bladder RNA (Fig 4B). MUC1 showed positive signal in LS174T cell line RNA, MUC5 and MUC6 showed positive signal in human stomach RNA (unpublished results).

To study mucin biosynthesis in UC and to compare this with normal colonic mucin biosynthesis, four biopsy specimens from a control patient with irritable bowel syndrome and four biopsy specimens from a patient with moderately active UC were taken at endoscopy. One specimen from each patient was pulse labelled with ${ }^{35} \mathrm{~S}$ ] amino acids and another with $\left[{ }^{35} \mathrm{~S}\right]$ sulphate. The third specimen was chase incubated after labelling with ${ }^{35} \mathrm{~S}$ ] amino acids and the fourth was chase incubated after labelling with $\left[{ }^{35} \mathrm{~S}\right]$ sulphate. Media of the four hour chase incubations of both the $\left[{ }^{35} \mathrm{~S}\right]$ amino acids and the $\left[{ }^{35} \mathrm{~S}\right]$ sulphate labelling were collected. Mucin from all samples was immunoprecipitated with antiHCM and analysed on SDS-PAGE (Fig 5). Anti-HCM was used here, because it has been shown to cross react with peptide epitopes of HCCM (Figs 1, 2, and 3) and it was shown to immunoprecipitate HCCM with higher efficiency than anti-HCCM (Fig 3). The pattern of $\left[{ }^{35} \mathrm{~S}\right]$ amino acids labelled protein bands in both normal and UC homogenates showed high similarity (Fig 5A). In the $\left.{ }^{35} \mathrm{~S}\right]$ amino 

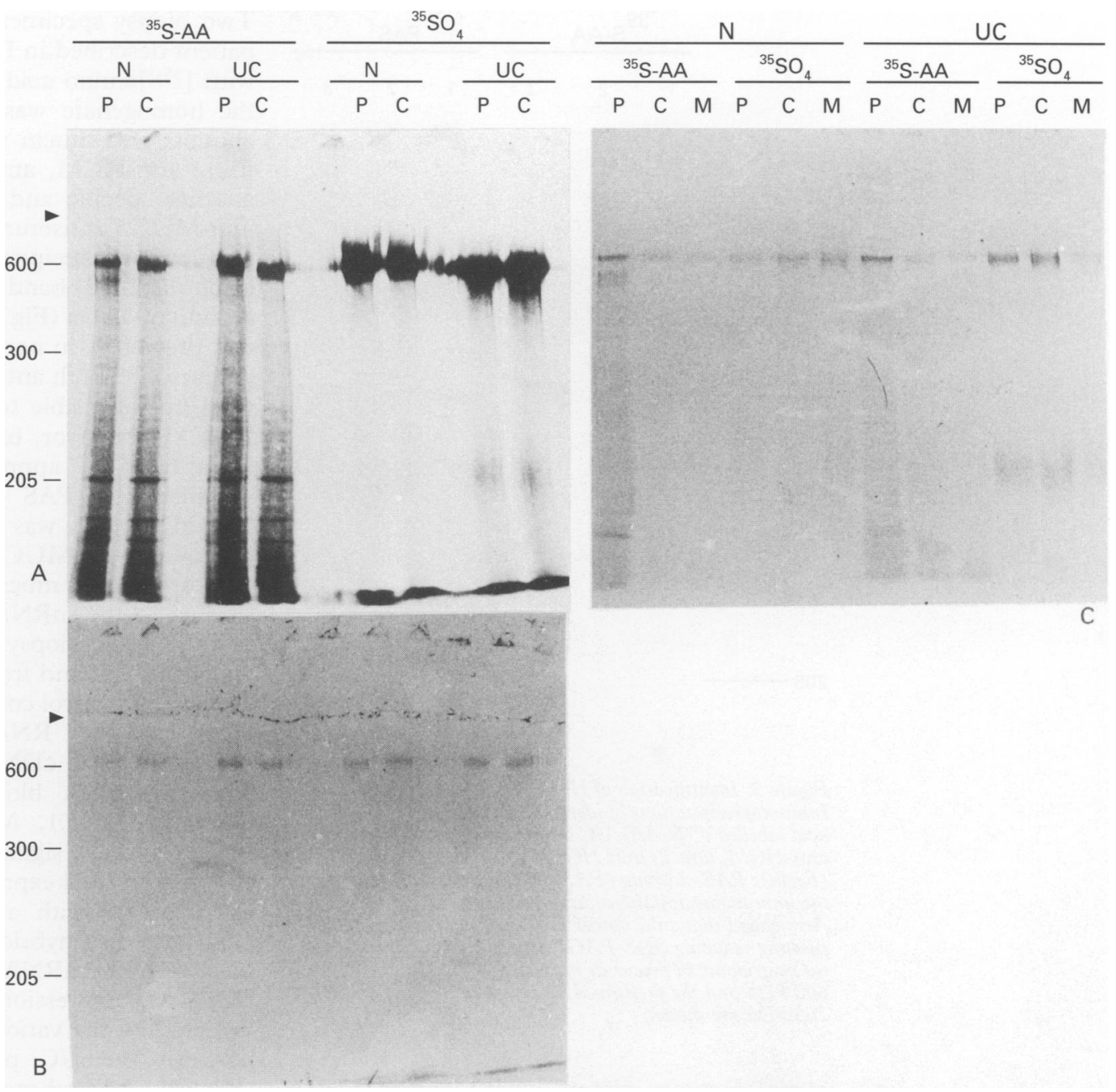

Figure 5: Biosynthesis of UC colonic mucin compared with normal colonic mucin. (A) Fluorography of normal $(N)$ or ulcerative colitis $(U C)$ homogenate after metabolic labelling with $\beta^{55}$ S]amino acids $\left.{ }^{35} S-A A\right)$ or $\left[{ }^{5} S\right.$ sulphate $\left({ }^{5} S O_{4}\right)$, after pulse labelling for 45 minutes $(P)$ or chase incubation of four hours $(C)$. (B) PAS staining of the gel shown in $(A)$. $(C)$ Fluorography of the homogenates depicted in $(A)$, immunoprecipitated with anti-HCM after pulse labelling $(P)$ or chase incubation (C) or from the media (M) after four hour chase incubation. Arrowheads show borders between $3 \%$ stacking and 4\% running reducing SDS-PAGE. In left margin unreduced rat gastric mucin precursor marker of $300 \mathrm{kDa}$ and $600 \mathrm{kDa}$ and the prestained high molecular mass marker of $205 \mathrm{kDa}$ are shown.

acids pulse labelled homogenates, a prominent high molecular weight band of approximately $660 \mathrm{kDa}$ can be distinguished, which showed a shift to about $550 \mathrm{kDa}$ in the chase incubations, both in the normal and in the UC homogenate. Metabolic sulphation of normal and UC homogenates did not show profound differences: an approximately $550 \mathrm{kDa}$ band was prominently present, both in normal as well as in UC homogenate. The concomitant PAS staining of the gel containing the homogenates showed that only the $550 \mathrm{kDa}$ band could be stained by PAS, both in normal as well as in UC homogenates (Fig 5B). Figure $5 \mathrm{C}$ depicts immunoprecipitated colonic mucin from normal colon compared with UC colon. In UC and in normal tissue, the mucin precursor is synthesised as a $600 \mathrm{kDa},\left[{ }^{35} \mathrm{~S}\right]$ aminoacids labelled product. After $O$-glycosylation and sulphation, mature HCCM acquired a mobility of $550 \mathrm{kDa}$ and was secreted into the medium (Fig 5C). $\left[{ }^{35} \mathrm{~S}\right]$ Sulphate labelling only showed the mature HCCM, already after 45 minute pulse labelling, with a molecular mass of approximately $550 \mathrm{kDa}$, which was also immunoprecipitated from the medium
(Fig 5C). Comparison of immunoprecipitated HCM and HCCM with the radiolabelled homogenates showed that the prominent bands in the homogenates have similar mobilities as the immunoprecipited precursors as well as the immunoprecipitated mature mucins. When Fig 5A and 5C are compared, it is obvious that immunoprecipitations were not quantitative. This does not impair the main finding in our studies, namely that biosynthesis of colonic mucin in UC is qualitatively highly comparable with MUC2 biosynthesis in normal colon.

\section{Discussion}

Previously, we have identified MUC2 as the major colonic mucin in the human colon. ${ }^{15}$ The aims of this study were to discover if MUC2 remains the major secretory mucin in colon affected by UC and secondly, to compare, qualitatively, the biosynthesis of normal and UC colonic mucin. Therefore, an identical protocol was followed to that for the isolation of normal colonic mucin. ${ }^{15}$ After isolation of HCCM, we compared amino acid composition 
with that of HCM. Even though it is generally difficult to determine exact amino acid compositions, HCCM and HCM seem to resemble each other, with high amounts of serine, threonine, and proline residues, although the ratios are not identical. The amino acid composition of HCCM resembled the amino acid composition deduced from the MUC2 cDNA sequence. ${ }^{445}$ Carbohydrate analysis showed the six monosaccharides known to be present in mucins. Similar to HCM, high amounts of sialic acid were detected in HCCM, as was also shown recently by others, ${ }^{46}$ while higher relative amounts of fucose were detected compared with HCM. It is known that in UC as well as in carcinoma, blood group determinants containing fucose appear, suggesting unmasking of these determinants on truncated oligosaccharide side chains, which could well account for a higher relative content of fucose in UC. ${ }^{52}$ Buoyant density of HCCM was lower compared with HCM. If HCCM consists of the same protein as HCM, this would suggest that HCCM contains less glycosylation compared with HCM, which would be in agreement with the diminished mean length of the $O$-linked oligosaccharides as described. 51947

Comparison of PAS stained HCCM and HCM on low percentage SDS-PAGE showed in both purified specimens one high molecular weight band with comparable mobilities. In homogenates from both normal and UC colon, a similar band was prominently present. Both anti-HCCM and anti-HCM antisera were shown to react mainly with proteinase sensitive peptide parts of HCM as well as HCCM. This cross reactivity of anti-HCCM for HCM and anti-HCM for HCCM suggests the presence of identical peptide epitopes in HCCM and HCM. On western blots of homogenates, a high molecular weight band was predominantly recognised with either antiserum, while to some degree, bands of higher mobilities were also recognised. For anti-HCM we have previously shown that saturation of the antiserum with purified HCM abolished all reactivity, not only towards the high molecular weight band, but also towards the bands of lower molecular weights. ${ }^{15}$ This suggests that the bands of lower molecular weight are probably mucin degradation products. Although anti-HCCM also recognised similar bands from normal as well as UC homogenates, the recognition pattern is different when compared with the recognition pattern of anti-HCM of normal and UC homogenates. At the present, we have no clear explanation for this phenomenon. We suggest that these independently raised antisera recognise slightly different subsets of peptide epitopes on the mucins. Moreover, the amounts of these degradation products is easily overestimated, as these low molecular weight products are far more efficiently blotted onto nitrocellulose than the higher molecular weight mucin. Nevertheless, it is probable that in UC one major mucin is synthesised, which has a similar mobility on SDS-PAGE as HCM and has similar peptide epitopes as HCM. Anti-HCM has previously been shown to react specifically with MUC2. ${ }^{15}$ Cross reactivity of anti-HCM with peptide epitopes of HCCM in western blotting suggests identical peptide epitopes between HCCM and MUC2.

Specificity of anti-HCCM for mucins is further illustrated by histochemistry. Alcian blue in particular stained all colonic goblet cells containing negatively charged mucins. Immunohistochemistry with anti-HCCM as well as anti-HCM showed exclusive staining of all goblet cells. Both antisera showed heterogeneous staining patterns, for which we presently have no clear explanation. It may well be a fixation artefact, as mucus is difficult to fix and one cell may be better fixed than the other. Secondly, it may be caused by different amounts of stored mucin per goblet cell. It is clear, however, that both antisera react with colonic goblet cells, showing that cross reactivity also exists at the histological level.

We suspected that HCCM, like HCM, would be identical to MUC2. Therefore, we studied this both at the protein and mRNA level. The $\left[{ }^{35} \mathrm{~S}\right]$ amino acids labelled MUC2 precursor could be immunoprecipitated with anti-MRP, a specific anti-MUC2 antiserum, as well as with anti-HCCM and anti-HCM. AntiMRP showed strongest reactivity. This is probably because of the higher titre of the anti-MRP antiserum. From the PAS staining it was visible that anti-HCCM as well as antiHCM also recognise the mature MUC2. In contrast, anti-MRP showed virtually no immunoprecipitation of PAS stainable mature HCCM, because the peptide epitopes of the tandem repeat region of MUC2 are not recognised after full $O$-glycosylation. Overall, we conclude that HCCM is MUC2.

This was also shown on mRNA level. On northern blot analysis, strong hybridisation could be seen, using a MUC2 probe, both for RNA isolated from healthy as well as UC colonic biopsy specimens. In contrast, little hybridisation could be detected using a MUC4 probe and virtually no hybridisation with MUC1, MUC3, MUC5, and MUC6 probes. This shows, that MUC2 remains the major mucin expressed in colon of patients with UC compared with controls.

Raising polyclonal antisera against the protruding peptide parts of mucin proves essential in studying biosynthesis of mucins, as these antisera will be able to recognise not only the precursor protein, but also the mature glycoprotein, independent of the degree of $\mathrm{O}$-glycosylation, as we have described. ${ }^{28} 3848$ Previously, we have shown that HCM is synthesised as a mucin precursor of around $600 \mathrm{kDa}$, which can only be labelled by $\left[{ }^{35} \mathrm{~S}\right]$ amino acids and not by $\left.{ }^{35} \mathrm{~S}\right]$ sulphate, nor can it be stained by PAS. This $600 \mathrm{kDa}$ precursor is not secreted into the medium. In time, however, the $\left.{ }^{35} \mathrm{~S}\right]$ amino acid labelled precursor becomes $O$-glycosylated and acquires an anomalous mobility on SDSPAGE of approximately $550 \mathrm{kDa}$. The mature, ' $550 \mathrm{kDa}$ ' mucin, can be metabolically labelled by $\left.{ }^{35} \mathrm{~S}\right]$ sulphate and can be stained by PAS 
after SDS-PAGE. It is secreted into the medium and comigrates with the isolated HCM. ${ }^{15}$ From gel filtration experiments, it became clear that mature HCM was far larger than $550 \mathrm{kDa}$, so the mobility of HCM on SDS-PAGE was concluded to be anomalous. ${ }^{15}$ In this respect it is interesting that we previously were able to show that rat colon prominently expresses a MUC2 homologue. ${ }^{48}$ The biosynthesis of this rat colonic MUC2 is very similar to the human colonic MUC2: the rat MUC2 precursor is approximately $600 \mathrm{kDa}$ and the secreted precursor has an anomalous mobility of approximately $650 \mathrm{kDa}$ on SDSPAGE. The molecular mass of mature rat MUC2 was shown by gel filtration to be much greater than $650 \mathrm{kDa}{ }^{48}$ The reasons for this anomalous mobility are not completely clear. However, we have shown for $\mathrm{HCM}^{15}$ and for rat MUC2 ${ }^{48}$ as well as for HCCM (data not shown), that these mucins show very similar mobilities on PAGE, independent of saturation with SDS, indicating that mobility of these mucins is intrinsically determined and may in part result from their high negative charge. ${ }^{49}$

In UC, MUC2 is also synthesised as a 600 $\mathrm{kDa}$ precursor. Restriction fragment length polymorphism has been described for the MUC2 gene, caused by variation in the number of tandemly repeated amino acid sequences. ${ }^{50}$ In all our studies, however, either with biopsy specimens from healthy controls as well as from UC patients, we always detected MUC2 biosynthetically as one, rather sharp delineated band of about $600 \mathrm{kDa}$. So far, we have no clear explanation for the discrepancy between the described variation in length of the MUC2 gene and the absence of size variation in the MUC2 protein product. It may be that the SDS-PAGE gels used have a too small resolution within the high molecular mass ranges to detect differences in molecular mass. After glycosylation and sulphation MUC2 acquired a slightly higher mobility on SDSPAGE of approximately $550 \mathrm{kDa}$. Only the $550 \mathrm{kDa}$ glycoprotein, which was sulphated, was secreted into the medium. The difference in mobility between the precursor of $600 \mathrm{kDa}$ and the mature mucin with an apparent molecular mass of $550 \mathrm{kDa}$ was small, but was always, although at times difficult, visible in five separate experiments with UC biopsy specimens. As the mobility of mature colonic MUC2 is anomalous on SDS-PAGE, it is very difficult to study differences in glycosylation using this technique.

In contrast with other studies, which found a lag period of six hours, ${ }^{51}$ secretion of $\left[{ }^{35} \mathrm{~S}\right]$ sulphate labelled MUC2 could already be detected after one hour chase incubation (data not shown) and was more pronounced after four hours chase incubation, both in normal as well as in UC colon. When metabolically labelled homogenates were analysed on SDSPAGE, it became clear, that the $\left[{ }^{35} \mathrm{~S}\right]$ amino acid labelled protein profiles of both homogenates did not differ significantly, suggesting that no important changes in biosynthesis of major proteins with molecular masses ranging from 80 to $>600 \mathrm{kDa}$ are present in
UC. This study shows that the major mucin expressed in UC is MUC2, but changes in quantity or structure of the oligosaccharide side chains are quite possible. Furthermore, it is important to note, that immunoprecipitation is not quantitative because of technical constraints. Therefore, only qualitative information on biosynthesis of MUC2 is provided. The $\left[{ }^{35} \mathrm{~S}\right]$ sulphate labelled homogenate showed, that sulphation does not seem to be changed dramatically in UC. As biopsy specimens are known to differ in size, however, it is premature to make firm conclusions on quantities of MUC2.

In conclusion, when isolating colonic mucin from colon affected by UC, MUC2 is predominantly isolated. Moreover, MUC2 biosynthesis does not seem to be qualitatively changed, compared with MUC2 synthesis in healthy colon. Quantitative studies are presently being undertaken, however, to examine possible changes in the rate of biosynthesis, secretion, and structure.

This work was supported by the Netherlands Organisation for Scientific Research (KMAJT); Nutricia, Zoetermeer (HAB); Scientic and the Netherlands Digestive Diseases Foundation (AWCE) The authors would like to thank Mrs C Koeleman from the Free University, Amsterdam and Mr A Leegwater, from the Academic Medical Centre, Amsterdam, for their skilful assistance in the carbohydrate and amino acid analysis respectively, and Dr L Klomp, from the Academic Hospital in Utrecht, from whom the MUC5A/C probe was obtained and Dr $\mathrm{H}$ Vos, from the Netherlands Cancer Institute (NKI, Amsterdam), from whom MUC1, 2, 3, and MUC4 probes were obtained.

1 Podolsky DK. Inflammatory bowel disease. Review article, part one. N Engl f Med 1991; 13: 928-38.

2 Podolsky DK. Inflammatory bowel disease. Review article, part two. N Engl f Med 1991; 14: 1008-17.

3 Strous GJ, Dekker J. Mucin-type glycoproteins. Crit Rev Biochem Mol Biol 1992; 27: 57-92.

4 Hounsell EF, Feizi T. Gastrointestinal mucins. Structure and antigenicities of their carbohydrate chains in health and disease. Med Biol 1982; 60: 227-36.

5 Feizi T, Gooi HC, Childs RA, Picard JK, Uemura K, Loomes LM, et al. Colloquium on mucin type glycoproteins. Biochem Soc Trans 1984; 12: 591-6.

6 Allen A. Mucus - a protective secretion of complexity. Trends Biochem Sci 1983; 8: 169-74.

7 Ligtenberg MJL, Vos HL, Gennissen AMC, Hilkens J. Episialin, a carcinoma associated mucin, is generated by a polymorphic gene encoding splice variants with alternative amino termini. f Biol Chem 1990; 265: 5573-8.

8 Gum JR, Byrd JC, Hicks JW, Toribara NW, Lamport DTA, Kim YS. Molecular cloning of human intestinal mucin cDNAs. Sequence analysis and evidence for genetic poly morphism. f Biol Chem 1989; 264: 6480-7.

9 Gum JR, Hicks JW, Swallow DM, Lagace RL, Byrd JC, Lamport DTA, et al. Molecular cloning of cDNAs derived from a novel human intestinal mucin gene. Biochem Biophys Res Comm 1990; 171: 407-15.

10 Porchet N, van Cong N, Dufosse J, Audie JP, GuyonnetDuperat V, Gross MS, et al. Molecular cloning and Duperat V, Gross MS, et al. Molecular cloning and bronchial mucin cDNA containing tandemly repeated bronchial mucin cDNA containing tandemly repeated sequences of 48 base

11 Toribara NW, Roberton AM, Ho SB, Kuo W-L, Gum E, Hicks JW, et al. Human gastric mucin. Identification of a unique species by expression cloning. $\mathcal{F}$ Biol Chem 1993; 268: $5879-85$.

12 Bobek LA, Tsai H, Biesbrock AR, Levine MJ. Molecular cloning, sequence and specificity of expression of the gene encoding the low molecular weight human salivary mucin (MUC7). F Biol Chem 1993; 268: 20563-70.

13 Shankar V, Gilmore MS, Elkins RC, Sachdev GP. A novel human airway mucin cDNA encodes a protein with unique tandem repeat organization. Biochem 7 1994; 300: 295-8.

14 Meerzaman D, Charles P, Daskal E, Polymeropoulos MH, Martin BM, Callaghan Rose M. Cloning and analysis of cDNA encoding a major airway glycoprotein, human tracheobronchial mucin (MUC5). 7 Biol Chem 1994; 269: 12932-9.

15 Tytgat KMAJ, Büller HA, Opdam FJM, Kim YS, Einerhand AWC, Dekker J. Biosynthesis of human colonic mucin: MUC2 is the prominent secretory mucin. Gastroenterology 1994; 107: 1352-63.

16 Tytgat KM, Dekker J, Büller HA. Mucins in inflammatory bowel disease. Eur $\mathcal{f}$ Gastroenterol Hepatol 1993; 5: 119-28. 
17 Jacobs LR, Huber PW. Regional distribution and alterations of lectin binding to colorectal mucin in mucosal biopsies from controls and subjects with inflammatory bowel disease. $\mathcal{f}$ Clin Invest $1985 ; 75: 112-8$.

18 Pullan RD, Thomas GAO, Rhodes $M$, Newscombe RG, Williams GT, Allen A, et al. Thickness of adherent mucus Williams GT, Allen A, et al. Thickness of adherent mucus
gel on colonic mucosa in humans and its relevance to gel on colonic mucosa in h
colitis. Gut 1994; 35: 353-9.

19 Clamp JR, Fraser G, Read AE. Study on the carbohydrate content of mucus glycoproteins from normal and diseased colon. Clin Sci 1981; 61: 229-34.

20 Boland CR, Lance P, Levin B, Riddell RH, Kim YS Abnormal goblet cell glycoconjugates in rectal biopsie associated with an increased risk of neoplasia in patients with ulcerative colitis: early results of a prospective study. Gut 1984; 25: 1364-71.

21 Ehsanullah M, Filipe MI, Gazzard B. Mucin secretion in inflammatory bowel disease: correlation with disease inflammatory bowel disease: correlation

22 Rhodes JM. Mucus and mucosal glycoproteins; the key to colitis and cancer? Gut 1989; 30: 1660-6.

23 Allen DC, Connoly NS, Biggart JD. Mucin profiles in ulcerative colitis with dysplasia and carcinoma. Histopathology 1988; 13: 413-24

24 Jass JR, Roberton AM. Colorectal mucin histochemistry in health and disease. A critical review. Pathol Int 1994; 44: 487-504.

25 Culling CFA, Reid PE, Dunn WL. A histochemical comparison of the $O$-acylated sialic acids of the epithelial mucins in ulcerative colitis, Crohn's disease, and normal controls. f Clin Pathol 1979; 32: 1272-7.

26 Agawa S, Muto A, Moriaka Y. Mucin abnormality in ulcerative colitis associated with carcinoma and/or dysplasia. Dis Colon Rectum 1988; 31: 387-9.

27 Truelove SC, Richards WCD. Biopsy studies in ulcerative colitis. BMF 1956; 1: 1315-8.

28 Tytgat KMAJ, Klomp LWJ, Bovelander F-J, Opdam FJM, Van der Wurff A, Einerhand AWC, et al. Preparation of anti-mucin polypeptide antisera to study mucin biosynthesis. Anal Biochem 1995; 226: 331-41.

29 Laemmli UK. Cleavage of structural proteins during the assembly of the head bacteriophage T4. Nature 1970;227 680-5.

30 Konad G, Offner H, Mellah J. Improved methods for staining of glycoproteins in polyacrylamide gels. Experientia 1984; 40: 303-4.

31 François C, Marshall RD, Neuberger A. Carbohydrates in protein. The determination of mannose in hen's egg albuprotein. The determination of mannose in hen's egg albu-
min by radioisotope dilution. Biochem $\mathcal{F}$ 1962; 83: 335-41.

min by radioisotope dilution. Biochem f 1962; 83:
32 Savage AV, Koppen PL, Schiphorst WECM, Trippelvitz LAW, Van Halbeek H, Vliegenthart JFG, et al. Porcine submaxillary mucin contains $\alpha 2 \rightarrow \alpha 3$ - and $\alpha 2 \rightarrow \alpha 6$ - linked $N$-acetyl and $N$-glycolyl-nearaminic acid. Eur $\mathcal{f}$ Biochem 986; 160: 123-9.

33 Van Eijk HM, Van der Heijden MA, Van Berlo CL, Soeters PB. Fully automated liquid-chromatographic determination of amino acids. Clin Chem 1988; 34: 2510-3.

34 Ho SB, Niehans GA, Lyftogt C, Shayan P, Cherwitz DL Gum ET, et al. Heterogeneity of mucin gene expression in normal and neoplastic tissues. Cancer Res 1993; 53: 641-51.

35 Rings EHHM, De Boer PAJ, Moorman AEM, Van Beers
EH, Dekker J, Montgomery RK, et al. Lactase gene expression during early development of rat small intestine. Gastroenterology 1992; 103: 1154-61.

36 Romeis B. Mikroskopiche Technik. München: R Oldenbourg Verlag, 1969: 164

37 Pearse AGE. Histochemistry, theoretical and applied. London: J \& A Churchill, 1968: 344-9.

38 Dekker J, Strous GJ. Covalent oligomerization of rat gastric mucin occurs in the rough endoplasmic reticulum, is $\mathrm{N}$-glycosylation dependent and precedes initial $O$-glycosylation. F Biol Chem 1990; 265: 18116-22.

39 Gendler SJ, Taylor-Papadimitriou J, Duhig T, Rothbard J, Burchell J. A highly immunogenic region of a human polymorphic epithelial mucin expressed by carcinomas is made up of tandem repeats. F Biol Chem 1988; 263: 12820-3.

40 Gendler SJ, Lancaster CA, Taylor-Papadimitriou J, Duhig $\mathrm{T}$, Peat N, Burchell J, et al. Molecular cloning and expression of a human tumor-associated polymorphic epithelial mucin 7 Biol Chem 1990; 265: 15286-93.

41 Klomp LWJ, Van Rens L, Strous GJ. Cloning and analysis of human gastric mucin cDNA reveals two types of conof human gastric mucin cDNA reveals two types of con831-8.

42 Sambrook J, Fritsch EF, Maniatis T. Molecular cloning: a laboratory manual. New York: Cold Spring Harbor Laboratory Press, 1989.

43 Church GM, Gilbert W. Genomic sequencing. Proc Natl Acad Sci USA 1984; 81: 1991-5.

44 Gum JR Jr, Hicks JW, Toribara NW, Rothe E-M, Lagace RE, Kim YS. The human MUC2 intestinal mucin has cysteine-rich subdomains located both upstream and downstream of its central repetitive region. $\mathcal{F}$ Biol Chem 1992; 267: 21375-83.

45 Gum JR Jr, Hicks JW, Toribara NW, Siddiki B, Kim YS Molecular cloning of intestinal mucin (MUC2) cDNA Identification of the amino terminus and sequence similarity to prepro-van Willebrand factor. $f$ Biol Chem 1994; larity to prepro-

46 Parker N, Tsai HH, Ryder SD, Raouf AH, Rhodes JM. Increased rate of sialylation of colonic mucin by cultured ulcerative colitis mucosal explants. Digestion 1995; 56: $52-6$

47 Boland CR, Clapp NK. Glycoconjugates in the colon of new world monkeys with spontaneous colitis. Association between inflammation and neoplasia. Gastroenterology 1987; 92: 625-34.

48 Tytgat KMAJ, Bovelander F-J, Opdam FJM, Einerhand AWC, Büller HA, Dekker J. Biosynthesis of rat MUC2 and its analogy with human MUC2. Biochem $\mathcal{f} 1995 ; 309$ : and its $221-9$.

49 Tytgat KMAJ, Swallow DM, Van Klinken BJW, Büller HA, Dekker J. Unpredictable behaviour of mucins in SDS polyacrylamide gel electrophorsis. Biochem $\mathcal{F}$ 1995; 310 1053-4.

50 Toribara NW, Gum J, Culhane PJ, Lagace RE, Hicks JW, Petersen GM. MUC2 human small intestinal mucin gen structure. Repeated arrays and polymorphism. If Clin Invest 1991; 88: 1005-13.

51 Finnie IA, Dwarakanath $\mathrm{AD}$, Taylor BA, Rhodes JM. Colonic mucin biosynthesis is increased by sodium butyrate. Gut 1995; 36: 92-9. 